\title{
Epidermal barrier: Adverse and beneficial changes induced by ultraviolet $B$ irradiation depending on the exposure dose and time (Review)
}

\author{
FELICIA PERMATASARI, BINGRONG ZHOU and DAN LUO \\ Department of Dermatology, The First Affiliated Hospital of Nanjing Medical University, \\ Nanjing, Jiangsu 210029, P.R. China
}

Received March 15, 2013; Accepted June 17, 2013

DOI: $10.3892 /$ etm.2013.1175

\begin{abstract}
Exposure of the skin to ultraviolet (UV) radiation induces various harmful effects in the tissues, particularly disruption of the epidermal barrier. However, ultraviolet B (UVB) irradiation has been applied in the treatment of atopic dermatitis, a skin disease in which the epidermal barrier is defective. We reviewed the homeostasis of the epidermal barrier and several studies investigating the adverse and beneficial effects caused by different doses of UVB irradiation in the epidermal barrier. It may be concluded that, despite the harmful effects of UVB irradiation on the skin, UVB irradiation is able to exert beneficial effects in the epidermal barrier when administered in suberythemal doses and over a relatively short period of time, with no clinically evident inflammation or barrier disruption. This may be a useful therapeutic strategy for the use of UVB irradiation in the treatment of skin diseases with a disrupted epidermal barrier, such as atopic dermatitis, while reducing or avoiding the side-effects.
\end{abstract}

\section{Contents}

1. Introduction

2. Homeostasis of the epidermal barrier

3. Adverse effects induced by UVB in the epidermal barrier

4. Reduced levels of covalently bound Cer

5. Disrupted multilamellar structures in the intercellular space of the SC

6. Increased GlcCer levels

7. Disrupted epidermal calcium gradient

Correspondence to: Professor Dan Luo or Dr Bingrong Zhou, Department of Dermatology, The First Affiliated Hospital of Nanjing Medical University, 300 Guangzhou Road, Nanjing, Jiangsu 210029, P.R. China

E-mail: daniluo2013@njmu.edu.cn

E-mail: bingrong.2002@163.com

Key words: epidermal barrier, ultraviolet B, suberythemal dose, covalently bound ceramides, calcium gradient, vitamin $\mathrm{D}_{3}$
8. Beneficial effects induced by UVB in the epidermal barrier 9. Conclusions

\section{Introduction}

The epidermal barrier is important for maintaining the homeostasis of the skin. The skin is constantly exposed to ultraviolet A (UVA) and ultraviolet B (UVB) irradiation while ultraviolet C radiation is absorbed by the ozone layer. Due to their different wavelength ranges, UVA and UVB act at two different levels of the skin. UVA predominantly affects the dermis and the DNA, whereas UVB affects the epidermis (1-3). UV irradiation of the skin is known to induce disruption of the epidermal barrier (4-7). However, UVB irradiation has been used for the treatment of atopic dermatitis, a skin disease involving a defective epidermal barrier (8-10). We reviewed the homeostasis of the epidermal barrier and the previous studies investigating the adverse and beneficial effects of UVB irradiation in the epidermal barrier, with the aim of understanding the potential therapeutic strategy of using UVB irradiation in the treatment of skin diseases with a disrupted epidermal barrier.

\section{Homeostasis of the epidermal barrier}

The skin barrier properties are primarily localized in the outer epidermal layer, the stratum corneum (SC) (11). The SC consists of corneocytes surrounded by a neutral lipid-enriched extracellular matrix. The mechanical strength of the skin is provided by the corneocytes, which are encased by a cornified cell envelope (CE) (12). The hydrophobic extracellular lipid matrix provides a barrier against the movement of water and electrolytes (11). Thus, the SC is involved in the regulation of water release from the organism and into the atmosphere, known as transepidermal water loss (TEWL) (13). TEWL is used as an indicator of the functional integrity of the SC $(14,15)$.

Lamellar bodies (LBs) are abundantly located in the differentiated keratinocytes, particularly in the stratum granulosum (16). LBs are responsible for supplying the lipids for the lipid envelope of the $\mathrm{CE}$ and the extracellular lipid matrix (Fig. 1) (16,17). LBs contain lipid precursors and numerous enzymes, including lipid hydrolases and proteases (16). It is considered that the incorporation of the lipid hydrolases and 
proteases into LBs requires the prior or concurrent delivery of lipids to the LBs (18). Thus, if lipids are deficient or lipid synthesis is disrupted, the enzymes that are characteristically found in LBs are not transported from the Golgi to the LBs (18). The lipids that constitute the extracellular matrix comprise $15 \%$ fatty acids, $25 \%$ cholesterol and $50 \%$ ceramides (Cer) (16). The relative quantities of these three key lipids are important for the formation of LBs. An excess or deficiency of a particular lipid may disturb LB formation (12).

In the normal human and murine epidermis, the extracellular calcium $\left(\mathrm{Ca}^{2+}\right)$ content is low in the basal and spinous layers, with a gradual increase from the inner to the outer layers and a maximal concentration within the outer stratum granulosum (19-21). The change in calcium concentration appears to be the primary signal inducing LB secretion (12). Following secretion from the granular cells into the intercellular space, these LB-derived lipids are further metabolized in the SC extracellular spaces by enzymes that are cosecreted in the LBs $(16,17,22-24)$. Specifically, $\beta$-glucocerebrosidase ( $\beta$-GlcCerase) converts glucosylceramides (GlcCer) into Cer $(25,26)$.

A minor but important component of the LB-derived lipids are acylglucosylceramides, of which approximately two-thirds are converted to $\omega$-hydroxyceramides that become covalently attached by ester linkages to the CE peptides (27-30). $\omega$-hydroxyceramides are the predominant lipid species of the corneocyte lipid envelope in the epidermis (31). These contain linoleic esters, which are linked by the action of transglutaminase-1 (TGase 1) to glutamine and to glutamate residues of a number of $\mathrm{CE}$ structural proteins, most notably involucrin $(30,32)$. These covalently bound Cer contribute a hydrophobic surface to the corneocyte that has important consequences for water barrier function by interactions with, and perhaps organization of, intercellular lipids (33).

\section{Adverse effects induced by UVB in the epidermal barrier}

Excessive exposure to UV radiation may lead to skin cancer and premature aging, and UVB is the most effective waveband at causing these changes (34-36). Exposure of the skin to UVB radiation may induce changes in the epidermal barrier (37).

\section{Reduced levels of covalently bound Cer}

Studies have demonstrated that the levels of covalently bound Cer are significantly reduced in parallel with significant increases in TEWL following irradiation with a single UVB dose of 75 or $160 \mathrm{~mJ} / \mathrm{cm}^{2}$, and following continuous UVB irradiation $\left[40 \mathrm{~mJ} / \mathrm{cm}^{2}\right.$ or $0.5 \mathrm{x}$ the minimal erythemal dose (MED)/day for 14 days] in hairless mice and rats $(38,39)$. This suggests a close correlation between the alteration of covalently bound Cer and the UVB-induced perturbation of the skin barrier.

It has been observed that the level of involucrin did not change following a single UVB irradiation at a dose of $50 \mathrm{~mJ} / \mathrm{cm}^{2}$; however, the expression of TGase $1 \mathrm{mRNA}$ was shown to be significantly downregulated $(38,40)$. Hirao et al (41) revealed that a reduction in the binding of $\omega$-hydroxyceramides to involucrin was elicited by UVB irradiation (41). Takagi et al (38) suggested that the UVB-induced

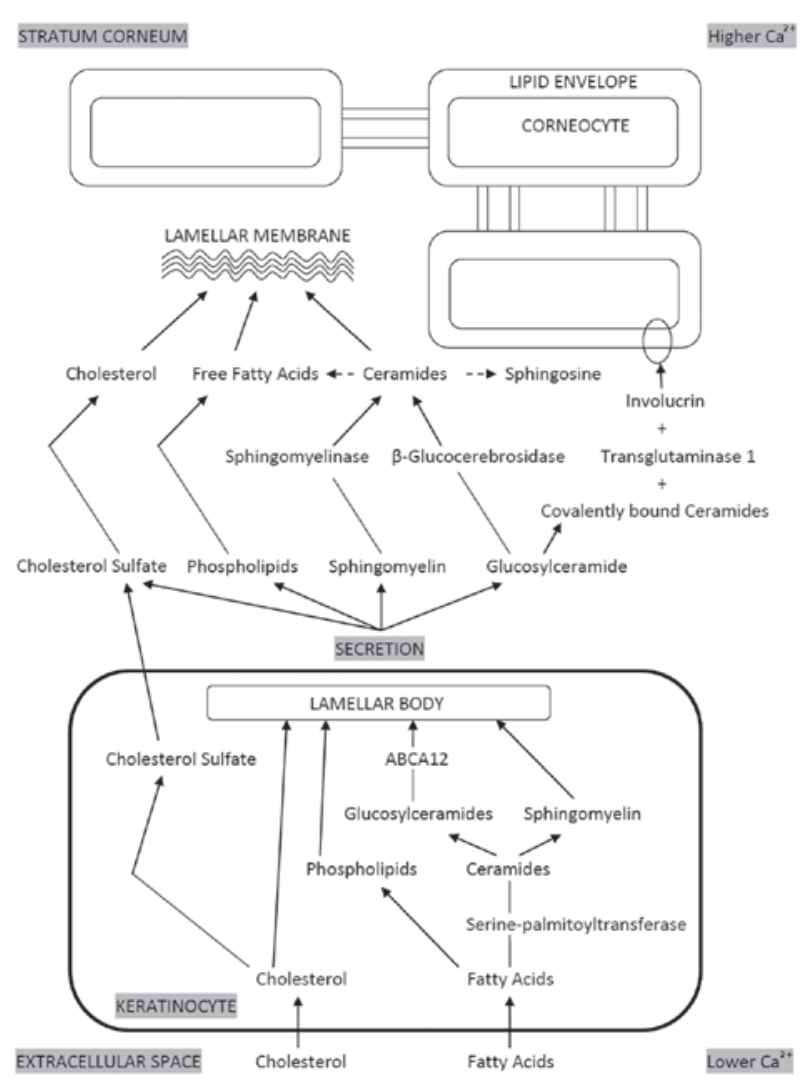

Figure 1. Pathways for the formation of the extracellular lamellar lipid membranes and the lipid envelope.

downregulation of TGase 1 may have been responsible for the observed reduction in the level of covalently bound Cer.

A study in which hairless mice were irradiated with a single $75 \mathrm{~mJ} / \mathrm{cm}^{2}$ dose of UVB radiation demonstrated that a reduction in the level of covalently bound Cer occurred in parallel with the time when the thickness of the epidermis was significantly increased (38). Treatments known to induce epidermal hyperplasia, such as tape stripping or sodium dodecylsulfate (SDS) treatment, led to significant reductions in the levels of covalently bound Cer, whereas the levels of non-bound Cer remained unchanged (38). This suggests that the decreased level of bound Cer is highly correlated with epidermal hyperplasia (38).

\section{Disrupted multilamellar structures in the intercellular space of the $\mathrm{SC}$}

LBs are secreted from the outer stratum granulosum cells (12). Acute disruption of the permeability barrier initiates a homeostatic repair response, including the rapid secretion (within minutes) of the contents of the LBs (50-80\% of pre-existing LBs are secreted) (42-44). A number of studies have demonstrated the suppression of LB release to the space between the SC and granulosa, and the retention of the LBs in the SC, following continuous UVB irradiation daily at a dose of $40 \mathrm{~mJ} / \mathrm{cm}^{2}$ or $0.5 \times \mathrm{MED} /$ day for $14-15$ days on hairless rats $(39,45)$. This may have contributed to the resulting disrupted multilamellar structures in the SC (folding, defects or absent). Bound Cer are considered to be formed by the fusion of LBs with the cell 
membrane of granulosum cells, followed by release into the space between the SC and granulosa (17). Meguro et al (39) suggested that the suppression of the release of the LBs into the space between the SC and the granulosa may have resulted in the reduction in covalently bound Cer in the SC following UVB irradiation (39).

A number of studies have shown that bound lipids may act as templates in the formation process of multilamellar structures by LBs released into the space between the SC and granulosa, and may be important in the maintenance of the multilamellar structures by connecting corneocytes to the multilamellar layer, acting as connectors between corneocytes or conferring resistance to proteinases derived from bacteria $(17,46,47)$. Several studies have demonstrated the importance of bound lipid for the formation of multilamellar structures between corneocytes $(39,48)$. In addition, certain studies have demonstrated the disruption of multilamellar structures together with decreased levels of covalently bound Cer following UVB irradiation $(38,39)$. Thus, the reduced levels of covalently bound Cer may contribute to the disruption of multilamellar structures. Covalently bound Cer and the formation of multilamellar structures by LB release may contribute reciprocally to enable normal function, while alterations induced by UVB irradiation affect the normal regulation of the two factors.

\section{Increased GlcCer levels}

Tagaki et al (49) observed markedly suppressed epidermal $\beta$-GlcCerase activity with a significantly increased expression of $\beta$-GlcCerase mRNA, followed immediately by the accumulation of GlcCer in the SC of hairless mice, one day subsequent to a single UVB irradiation dose of $70 \mathrm{~mJ} / \mathrm{cm}^{2}$ (49). Under normal conditions, $\beta$-GlcCerase exists at levels sufficient to convert all GlcCer secreted from lamellar granules into Cer, leading to complete loss of GlcCer in the SC. The accumulation of GlcCer in the SC resulting from the inhibition of $\beta$-GlcCerase activity leads, in turn, to barrier perturbation, concomitant with the abnormal lamellar integrity $(26,49,50)$.

It has been demonstrated that epidermal hyperplasia may be induced by elevated GlcCer levels (51); thus, the accumulation of GlcCer in the epidermis, as a result of the downregulation of $\beta$-GlcCerase, may be the cause of the hyperproliferation induced by UVB irradiation (49).

Decreased $\beta$-GlcCerase activity may occur due to damage to the enzyme itself. As $\beta$-GlcCerase is predominantly localized in the outer epidermis (52), its activity may be susceptible to UVB irradiation, resulting in an attenuated protein-generating capacity at specific cellular levels of the epidermis (49).

Between 70 and $80 \%$ of Cer are derived from GlcCer through the action of $\beta$-GlcCerase $(53,54)$. Decreased $\beta$-GlcCerase activity, induced by UVB, gives rise to the significant accumulation of GlcCer in the SC; however, it has been observed that this is not accompanied by a significant reduction in the Cer level in the SC (49). Tagaki et al (49) demonstrated that the increasing level of GlcCer in the SC following UVB irradiation corresponded to $<10 \%$ of the total Cer in the SC. It was suggested that $\beta$-GlcCerase activity exists below the $\mathrm{SC}$ at a level sufficient to convert more than the control level of GLcCer (49).

\section{Disrupted epidermal calcium gradient}

Jiang et al (55) revealed the appearance of large clumps of calcium precipitates in the extracellular spaces of the lower nucleated layers of the epidermis of hairless mice $48 \mathrm{~h}$ subsequent to UVB irradiation at a dose of $0.15 \mathrm{~J} / \mathrm{cm}^{2}$ (equivalent to $7.5 \mathrm{x}$ MED) (55). The normal calcium gradient was altered, with higher extracellular calcium levels within the lower layers of the epidermis (55). The most notable feature was observed 96 h subsequent to UVB irradiation, when the TEWL reached the highest level. Immediately following barrier disruption, the increased water movement through the compromised SC carried calcium outward toward the skin surface, resulting in a reduction in the calcium concentration surrounding the stratum granulosum cells $(20,56,57)$. A gradual return to a normal calcium distribution level was observed in parallel with the gradual return to a normal TEWL level (55), indicating that barrier recovery occurs in parallel with the restoration of the calcium gradient in the epidermis (20). This shows that a marked correlation exists between the altered calcium gradient and the disrupted epidermal barrier.

If the reduction in calcium levels is prevented by the provision of exogenous calcium, LB secretion does not occur and permeability barrier repair is not initiated (20,56-58). Conversely, if the calcium levels surrounding the stratum granulosum cells are decreased without disrupting the permeability barrier by either iontophoresis or sonophoresis, LB secretion is stimulated $(58,59)$. This shows that the calcium gradient in the epidermis is closely linked to the presence of a normal permeability barrier.

Several studies have investigated the UVB-induced abnormal lamellar membrane structures in the SC interstices $(38,39,60)$. Defective lamellar multilayers have also been observed in the presence of an altered calcium gradient following UVB irradiation (55). The altered calcium gradient following UVB irradiation may affect the secretion of LBs $(20,56,57)$. This may account for the suppression of LB release to the space between the $\mathrm{SC}$ and granulosa, and the retention of $\mathrm{LBs}$ in the $\mathrm{SC}$, following the continuous UVB irradiation of hairless rats daily at a dose of $40 \mathrm{~mJ} / \mathrm{cm}^{2}$ or $0.5 \times \mathrm{MED} / \mathrm{day}$ for $14-15$ days $(39,45)$. This may contribute to the observed abnormal lamellar membrane structures in the SC following UVB irradiation.

Abundant evidence supports the hypothesis that extracellular calcium regulates the progression of mammalian epidermal differentiation. In human and murine keratinocytes, low calcium concentrations stimulate proliferation, while high calcium concentrations inhibit proliferation and enhance differentiation (61). Moreover, it has been demonstrated that UVB irradiation induces a variety of cutaneous responses, including the induction of epidermal hyperplasia (55). Thus, it is conceivable that a critical level of cytosolic calcium is required for the initiation of the differentiation events. Therefore, the increases in the extracellular and cytosolic calcium levels are associated with the changes in the epidermal proliferation and/or differentiation process (55).

A study observed that following an increase in the calcium concentration, the TGase 1 enzyme activated glutamine residues $\left(\mathrm{Gln}^{107}, \mathrm{Gln}^{118}, \mathrm{Gln}^{122}, \mathrm{Gln}^{133}\right.$ and Gln ${ }^{496}$ ) of involucrin, with high specificity (32). Since cornified envelopes are 
present in the outer epidermis where the calcium concentration is normally higher, TGase 1 functions well in such a high calcium concentration. Therefore, the disruption of the epidermal calcium gradient caused by UVB irradiation may further downregulate TGase 1 enzyme activity, subsequently leading to the disruption of the formation of covalently bound Cer.

\section{Beneficial effects induced by UVB in the epidermal barrier}

Although narrowband UVB or UVA phototherapy is a mainstay of treatment, natural and artificial UVB irradiation is frequently employed in the treatment of atopic dermatitis $(9,10)$. Different skin types are affected differently by the same level of UVB exposure. The MED of a fair-skinned (Fitzpatrick type I) person is $10-25 \mathrm{~mJ} / \mathrm{cm}^{2}(62,63)$, while individuals with darker skin have a higher MED (64). Therefore, in UVB treatment, the skin type of the patient also determines the treatment dose. The exposure dose is an important factor in determining the effects of UVB exposure. UV-induced DNA damage and barrier disruption increase linearly with increasing dosage (7).

High doses of UVB, such as a dose 4-fold higher than the MED, are known to exert detrimental effects on permeability barrier function $(37,38,60)$. By contrast, low-dose UV phototherapy has been demonstrated to be useful for the treatment of a variety of skin disorders, including psoriasis and atopic dermatitis $(9,10,65)$. An erythemal dose ( $\geq 1$ x MED) may impair DNA repair mechanisms and lead to cell elimination via apoptosis $(66,67)$. A study of hairless mice irradiated with a single dose of $\sim 1$ x MED UVB $\left(75 \mathrm{~mJ} / \mathrm{cm}^{2}\right)$ showed significant disruption of the barrier (38). A study of human subjects irradiated with $0.7 \times$ MED UVB for 10 consecutive days revealed an unaltered expression of $\mathrm{p} 53$, a protein which is able to activate DNA repair proteins when DNA has sustained damage. This indicated that the repair systems were activated (67).

A study on hairless mice exposed to $0.5 \mathrm{x}$ MED UVB irradiation $\left(40 \mathrm{~mJ} / \mathrm{cm}^{2}\right)$ daily for 14 days demonstrated a significant reduction in the levels of covalently bound Cer and disrupted multilamellar structures (39). By contrast, a separate study concerning hairless mice irradiated with the same dose of UVB daily for 3 days demonstrated no clinically evident inflammation or barrier disruption (68). A dose of 0.5 x MED UVB irradiation for 3 days, prior to tape-stripping, resulted in significantly accelerated barrier recovery rates, implying that repeated, short-term exposure to low-dose UVB significantly accelerates the kinetics of barrier recovery following acute insults (68).

The irradiation of hairless mice with a $0.5 \times$ MED dose of UVB for 3 days demonstrated the positive effects of UVB on the epidermis, which, at least in part, were mediated by cutaneous vitamin $\mathrm{D}_{3}$ activation (68). In parallel with the upregulation of the cutaneous vitamin $\mathrm{D}_{3}$ system, there was an increase in the mRNA levels for the epidermal lipid synthetic enzymes, HMG-CoA, fatty acid synthase (FAS) and serine palmitoyl transferase (SPT) (68). There was also an upregulation of barrier-linked antimicrobial peptides (AMPs; LL-37 and hBD2) in the outer epidermis, which is considered to be mediated by the cutaneous production of $1,25(\mathrm{OH})_{2} \mathrm{D}_{3}$, the most active form of vitamin $\mathrm{D}_{3}$ (111). Increases in the expression of involucrin and filaggrin were also observed, without the concurrent development of epidermal hyperplasia, implying that UVB may also regulate epidermal differentiation (68).

$1,25(\mathrm{OH})_{2} \mathrm{D}_{3}$ has been demonstrated to increase the expression of a number of major epidermal differentiation proteins, including involucrin, loricrin, filaggrin and transglutaminase, as well as to stimulate cornified envelope formation (68). A suberythemal dose of UVB exposure is normally enough to generate the synthesis of sufficient vitamin $\mathrm{D}_{3}$ to impact downstream events in the epidermis (68). Another study on cultured human keratinocytes showed that irradiation with a single $23 \mathrm{~mJ} / \mathrm{cm}^{2}$ dose of UVB upregulated SPT activity, leading to increased sphingolipid synthesis (69).

\section{Conclusions}

In addition to TEWL acting as an indicator of the functional integrity of the SC, alterations in covalently bound Cer and the epidermal calcium gradient are closely associated with the disruption of the epidermal barrier.

A single high dose of UVB irradiation and suberythemal doses of UVB irradiation for 14 days have been demonstrated to exert negative effects on the epidermal barrier, leading to barrier disruption. By contrast, a low dose of UVB irradiation and suberythemal doses of UVB irradiation for 3 days have been demonstrated to exert positive effects on the epidermal barrier, without clinically evident inflammation or barrier disruption.

The present review therefore shows that, despite the known harmful effects, UVB irradiation may exert positive effects in the epidermal barrier when administered in low doses and over a relatively short period. This may be a useful therapeutic strategy for the use of UVB irradiation in the treatment of skin diseases with a disrupted epidermal barrier, such as atopic dermatitis, while reducing or avoiding the possible side effects. Further studies are required to determine the efficacy of low doses of UVB irradiation on the skin of patients with atopic dermatitis.

\section{Acknowledgements}

This study was supported by grants from the China National Natural Science Foundation (grant nos. 81000700 and 81171518).

\section{References}

1. Herrling T, Jung K and Fuchs J: Measurements of UV-generated free radicals/reactive oxygen species (ROS) in skin. Spectrochim Acta A Mol Biomol Spectrosc 63: 840-845, 2006.

2. Haywood R, Rogge F and Lee M: Protein, lipid, and DNA radicals to measure skin UVA damage and modulation by melanin. Free Radic Biol Med 44: 990-1000, 2008.

3. Bak H, Hong SP, Jeong SK, et al: Altered epidermal lipid layers induced by long-term exposure to suberythemal-dose ultraviolet. Int J Dermatol 50: 832-837, 2011.

4. McAuliffe DJ and Blank IH: Effects of UVA (320-400 nm) on the barrier characteristics of the skin. J Invest Dermatol 96: 758-762, 1991.

5. Abe T and Mayuzumi J: The change and recovery of human skin barrier functions after ultraviolet light irradiation. Chem Pharm Bull (Tokyo) 27: 458-462, 1979.

6. Solomon AE and Lowe NJ: Percutaneous absorption in experimental epidermal disease. Br J Dermatol 100: 717-722, 1979.

7. Lamaud E and Schalla W: Influence of UV irradiation on penetration of hydrocortisone. In vivo study in hairless rat skin. Br J Dermatol 111 (Suppl 27): S152-S157, 1984. 
8. Valkova S and Velkova A: UVA/UVB phototherapy for atopic dermatitis revisited. J Dermatolog Treat 15: 239-244, 2004.

9. Jekler J and Larkö O: UVB phototherapy of atopic dermatitis. Br J Dermatol 119: 697-705, 1988

10. Wulf HC and Bech-Thomsen N: A UVB phototherapy protoco with very low dose increments as a treatment of atopic dermatitis. Photodermatol Photoimmunol Photomed 14: 1-6, 1998.

11. Elias PM: The stratum corneum as an organ of protection: old and new concepts. Curr Probl Dermatol 18: 10-21, 1989.

12. Feingold KR: Thematic review series: skin lipids. The role of epidermal lipids in cutaneous permeability barrier homeostasis. J Lipid Res 48: 2531-2546, 2007.

13. Proksch E, Brandner JM and Jensen JM: The skin: an indispensable barrier. Exp Dermatol 17: 1063-1072, 2008.

14. Nilsson GE: Measurement of water exchange through skin. Med Biol Eng Comput 15: 209-218, 1977.

15. Pinnagoda J, Tupker RA, Agner T and Serup J: Guidelines for transepidermal water loss (TEWL) measurement. A report from the Standardization Group of the European Society of Contact Dermatitis. Contact Dermatitis 22: 164-178, 1990.

16. Elias PM and Feingold KR (eds): Skin Barrier. Taylor \& Francis New York, 2006.

17. Wertz PW: Epidermal lipids. Semin Dermatol 11: 106-113, 1992

18. Rassner U, Feingold KR, Crumrine DA and Elias PM: Coordinate assembly of lipids and enzyme proteins into epidermal lamellar bodies. Tissue Cell 31: 489-498, 1999.

19. Menon GK, Grayson S and Elias PM: Ionic calcium reservoirs in mammalian epidermis: ultrastructural localization by ion-capture cytochemistry. J Invest Dermatol 84: 508-512, 1985.

20. Menon GK, Elias PM, Lee SH and Feingold KR: Localization of calcium in murine epidermis following disruption and repair of the permeability barrier. Cell Tissue Res 270: 503-512, 1992.

21. Menon GK and Elias PM: Ultrastructural localization of calcium in psoriatic and normal human epidermis. Arch Dermatol 127: 57-63, 1991.

22. Freinkel RK and Traczyk TN: Lipid composition and acid hydrolase content of lamellar granules of fetal rat epidermis. J Invest Dermatol 85: 295-298, 1985.

23. Grayson S, Johnson-Winegar AG, Wintroub BU, Isseroff RR, Epstein EH Jr and Elias PM: Lamellar body-enriched fractions from neonatal mice: preparative techniques and partial characterization. J Invest Dermatol 85: 289-294, 1985.

24. Wertz PW, Downing DT, Freinkel RK and Traczyk TN: Sphingolipids of the stratum corneum and lamellar granules of fetal rat epidermis. J Invest Dermatol 83: 193-195, 1984.

25. Holleran WM, Ginns EI, Menon GK, et al: Consequences of beta-glucocerebrosidase deficiency in epidermis. Ultrastructure and permeability barrier alterations in Gaucher disease. J Clin Invest 93: 1756-1764, 1994.

26. Holleran WM, Takagi Y, Menon GK, Legler G, Feingold KR and Elias PM: Processing of epidermal glucosylceramides is required for optimal mammalian cutaneous permeability barrier function J Clin Invest 91: 1656-1664, 1993.

27. Hedberg CL, Wertz PW and Downing DT: The time course of lipid biosynthesis in pig epidermis. J Invest Dermatol 91: $169-174,1988$

28. Swartzendruber DC, Wertz PW, Madison KC and Downing DT: Evidence that the corneocyte has a chemically bound lipid envelope. J Invest Dermatol 88: 709-713, 1987.

29. Wertz PW, Madison KC and Downing DT: Covalently bound lipids of human stratum corneum. J Invest Dermatol 92: 109-111, 1989.

30. Marekov LN and Steinert PM: Ceramides are bound to structural proteins of the human foreskin epidermal cornified cell envelope. J Biol Chem 273: 17763-17770, 1998.

31. Behne M, Uchida Y, Seki T, de Montellano PO, Elias PM and Holleran WM: Omega-hydroxyceramides are required for corneocyte lipid envelope (CLE) formation and normal epidermal permeability barrier function. J Invest Dermatol 114: $185-192,2000$.

32. Nemes Z, Marekov LN, Fésüs L and Steinert PM: A novel function for transglutaminase 1: attachment of long-chain omega-hydroxyceramides to involucrin by ester bond formation. Proc Natl Acad Sci USA 96: 8402-8407, 1999.

33. Fitzpatrick TB, Eisen AZ, Wolff K, Freedburg IM and Austen KF (eds): Dermatology in General Medicine. 4th edition. McGraw-Hill, Health Professions Division, New York, 1993.

34. Cole CA, Forbes PD and Davies RE: An action spectrum for UV photocarcinogenesis. Photochem Photobiol 43: 275-284, 1986.
35. Sterenborg HJ, de Gruijl FR, Kelfkens G and van der Leun JC: Evaluation of skin cancer risk resulting from long term occupational exposure to radiation from ultraviolet lasers in the range from 190 to $400 \mathrm{~nm}$. Photochem Photobiol 54: 775-780, 1991.

36. Bissett DL, Hannon DP and Orr TV: Wavelength dependence of histological, physical, and visible changes in chronically UV-irradiated hairless mouse skin. Photochem Photobiol 50: 763-769, 1989.

37. Haratake A, Uchida Y, Schmuth M, et al: UVB-induced alterations in permeability barrier function: roles for epidermal hyperproliferation and thymocyte-mediated response. J Invest Dermatol 108: 769-775, 1997

38. Takagi Y, Nakagawa H, Kondo H, Takema Y and Imokawa G: Decreased levels of covalently bound ceramide are associated with ultraviolet B-induced perturbation of the skin barrier. J Invest Dermatol 123: 1102-1109, 2004.

39. Meguro S, Arai Y, Masukawa Y, Uie K and Tokimitsu I Relationship between covalently bound ceramides and transepidermal water loss (TEWL). Arch Dermatol Res 292: 463-468, 2000.

40. Bernerd F and Asselineau D: Successive alteration and recovery of epidermal differentiation and morphogenesis after specific UVB-damages in skin reconstructed in vitro. Dev Biol 183. 123-138, 1997.

41. Hirao T, Denda M and Takahashi M: Identification of immature cornified envelopes in the barrier-impaired epidermis by characterization of their hydrophobicity and antigenicities of the components. Exp Dermatol 10: 35-44, 2001.

42. Proksch E, Holleran WM, Menon GK, Elias PM and Feingold KR Barrier function regulates epidermal lipid and DNA synthesis. $\mathrm{Br}$ J Dermatol 128: 473-482, 1993

43. Grubauer G, Elias PM and Feingold KR: Transepidermal water loss: the signal for recovery of barrier structure and function. J Lipid Res 30: 323-333, 1989.

44. Menon GK, Feingold KR, Mao-Qiang M, Schaude M and Elias PM: Structural basis for the barrier abnormality following inhibition of HMG CoA reductase in murine epidermis. J Invest Dermatol 98: 209-219, 1992.

45. Meguro S, Arai Y, Masukawa K, Uie K and Tokimitsu I: Stratum corneum lipid abnormalities in UVB-irradiated skin. Photochem Photobiol 69: 317-321, 1999.

46. Wertz PW and Downing DT: Covalently bound omega-hydroxyacylsphingosine in the stratum corneum. Biochim Biophys Acta 917: 108-111, 1987

47. Abraham W and Downing DT: Interaction between corneocytes and stratum corneum lipid liposomes in vitro. Biochim Biophys Acta 1021: 119-125, 1990

48. Chang F, Swartzendruber DC, Wertz PW and Squier CA: Covalently bound lipids in keratinizing epithelia. Biochim Biophys Acta 1150: 98-102, 1993.

49. Takagi Y, Nakagawa H, Yaginuma T, Takema Y and Imokawa G: An accumulation of glucosylceramide in the stratum corneum due to attenuated activity of beta-glucocerebrosidase is associated with the early phase of UVB-induced alteration in cutaneous barrier function. Arch Dermatol Res 297: 18-25, 2005.

50. Haratake A, Uchida Y, Mimura K, Elias PM and Holleran WM Intrinsically aged epidermis displays diminished UVB-induced alterations in barrier function associated with decreased proliferation. J Invest Dermatol 108: 319-323, 1997.

51. Marsh NL, Elias PM and Holleran WM: Glucosylceramides stimulate murine epidermal hyperproliferation. J Clin Invest 95: 2903-2909, 1995.

52. Takagi Y, Kriehuber E, Imokawa G, Elias PM and Holleran WM Beta-glucocerebrosidase activity in mammalian stratum corneum. J Lipid Res 40: 861-869, 1999.

53. Hamanaka S, Hara M, Nishio H, Otsuka F, Suzuki A and Uchida Y: Human epidermal glucosylceramides are major precursors of stratum corneum ceramides. J Invest Dermatol 119: 416-423, 2002

54. Uchida Y, Hara M, Nishio H, et al: Epidermal sphingomyelins are precursors for selected stratum corneum ceramides. J Lipid Res 41: 2071-2082, 2000.

55. Jiang SJ, Chu AW, Lu ZF, Pan MH, Che DF and Zhou XJ: Ultraviolet B-induced alterations of the skin barrier and epidermal calcium gradient. Exp Dermatol 16: 985-992, 2007.

56. Lee SH, Elias PM, Proksch E, Menon GK, Mao-Quiang M and Feingold KR: Calcium and potassium are important regulators of barrier homeostasis in murine epidermis. J Clin Invest 89: $530-538,1992$. 
57. Menon GK, Elias PM and Feingold KR: Integrity of the permeability barrier is crucial for maintenance of the epidermal calcium gradient. Br J Dermatol 130: 139-147, 1994.

58. Lee SH, Choi EH, Feingold KR, Jiang S and Ahn SK: Iontophoresis itself on hairless mouse skin induces the loss of the epidermal calcium gradient without skin barrier impairment J Invest Dermatol 111: 39-43, 1998.

59. Menon GK, Price LF, Bommannan B, Elias PM and Feingold KR Selective obliteration of the epidermal calcium gradient leads to enhanced lamellar body secretion. J Invest Dermatol 102 : 789-795, 1994.

60. Holleran WM, Uchida Y, Halkier-Sorensen L, et al: Structural and biochemical basis for the UVB-induced alterations in epidermal barrier function. Photodermatol Photoimmunol Photomed 13: 117-128, 1997.

61. Hennings H, Michael D, Cheng C, Steinert P, Holbrook K and Yuspa SH: Calcium regulation of growth and differentiation of mouse epidermal cells in culture. Cell 19: 245-254, 1980

62. Taylor SC: Skin of color: biology, structure, function, and implications for dermatologic disease. J Am Acad Dermatol 46: (Suppl) S41-S62, 2002.

63. Pathak MA, Nghiem P and Fitzpatrick TB: Acute and chronic efects of the sun. In: Fitzpatrick's Dermatology in General Medicine. Freedberg IM, Eisen AZ, Wolff K, Austen LA, Goldsmith K, Katz SI and Fitzpatrick TB (eds). Vol 1.5th edition. McGraw-Hill, New York, pp 1598-1607, 1999.
64. Rigel EG, Lebwohl M, Rigel AC and Rigel DS: Daily UVB exposure levels in high-school students measured with digital dosimeters. J Am Acad Dermatol 49: 1112-1114, 2003.

65. Leenutaphong V, Nimkulrat P and Sudtim S: Comparison of phototherapy two times and four times a week with low doses of narrow-band ultraviolet B in Asian patients with psoriasis. Photodermatol Photoimmunol Photomed 16: 202-206, 2000.

66. Murphy M, Mabruk MJ, Lenane P, et al: Comparison of the expression of p53, p21, Bax and the induction of apoptosis between patients with basal cell carcinoma and normal controls in response to ultraviolet irradiation. J Clin Pathol 55: 829-833, 2002.

67. Narbutt J, Norval M, Slowik-Rylska M, et al: Suberythemal ultraviolet $\mathrm{B}$ radiation alters the expression of cell cycle-related proteins in the epidermis of human subjects without leading to photoprotection. Br J Dermatol 161: 890-896, 2009.

68. Hong SP, Kim MJ, Jung MY, et al: Biopositive effects of low-dose UVB on epidermis: coordinate upregulation of antimicrobial peptides and permeability barrier reinforcement. J Invest Dermatol 128: 2880-2887, 2008.

69. Farrell AM, Uchida Y, Nagiec MM, et al: UVB irradiation up-regulates serine palmitoyltransferase in cultured human keratinocytes. J Lipid Res 39: 2031-2038, 1998. 